\title{
Architecture and nature at the end of the 20th century: towards a dialogical approach for sustainable design in architecture
}

\author{
F. J. Soria López \\ Metropolitan Autonomous University, México City, México
}

\begin{abstract}
This essay approaches architecture from a humanist point of view, analyzing social dialogue in relation to design processes and architectural production, which search for a balanced interaction between the built environment and its natural and cultural settings. In a first approach architecture is considered as a 'second nature', one that is fit to meet man's needs, which goes beyond functional and pragmatic issues, and include in a fundamental way the spiritual aspects, those which ultimately define our human nature. In a second phase a historical-interpretative analysis is developed for a better understanding of the main practices in sustainable architecture over the last two decades of the 20th century. The concepts of dialogism and the hermeneutic trilogy (pre-figuration, con-figuration and re-figuration) developed by M. Bajtin and Paul Ricoeur, respectively, are explored as a methodological structure to analyze and interpret a sustainable architecture. The idea is to bind dialogism and sustainability as one concept, in order to approach architecture in an integral and holistic way, and to try to visualize it as a multidimensional cultural phenomenon. Here, the main hypothesis is explained, one which establishes that both, biophysical and tangible factors, as well as social and intangible ones, are indispensable cultural parameters to consider when designing a truly sustainable architecture.

Keywords: dialogical sustainability, sustainable architecture assessment, second nature, dialogical architecture, sustainable architecture, qualitative interpretation of space.
\end{abstract}

\section{Introduction}

During the 20th century contemporary society experimented diverse and profound transformations in the way its individuals communicate and relate with 
one another and with their surrounding environment, like never before in human history. Particularly in the last few decades the relation between man and nature has acquired great importance in our social conscience as we become aware how human action and production are progressively devastating the natural environment. In an intent to stop this environmental impact that affects the world as a whole, a great number of countries have adopted since the end of the 80's (Brundtland Report 1987) and the beginning of the 1990's (Earth Summit 1992) the concept of sustainable development defined as that social, politic and economic development that meets the needs of the present without compromising the ability of future generations to meet their own needs, as a way to reach a better quality of life for all societies and simultaneously preserve the natural environment.

Aware of this emerging problem, architectural practice has "reacted" strongly, and in the last few years we have seen many possible solutions: ecological architecture, green architecture, bioclimatic architecture, energy efficient architecture or simply sustainable architecture. This last term tries to gather all the previous design processes which incorporate strategies to evaluate, control and minimize the physical impact of the building on its surrounding environment. After making a critical analysis of the leading stances, it seems evident that these "sustainable" practices are dominated by a sort of scientific or environmentalist posture, that understands architectural design as subordinated or dominated mainly by external relations: that is, physical, tangible and quantifiable conditions, adopting certain pre-established parameters such as form, maximum contamination rates, energy standards, etc. This posture seems to lead to an "ecological determinism", when designing cultural objects with much more complex characteristics.

\section{Sustainable architecture or environmental engineering?}

In the past few decades the main environmental design processes in architecture and most of the normative regulations applied focus on diminishing the ecological footprint (not interrupting, modifying or destroying natural ecosystems) and are sustainable as long as they use, within certain limits, the natural resources (renewable energy, biodegradable materials, residue treatment) intended basically to reduce its physical impact on nature, at both local and global levels.

On the other hand much of the literature, as well as many educational programs about green, sustainable, environmental or ecological architecture talk about the urgent need to "establish a new relationship with the natural environment" [3] as part of the responsibility of the architect that must not be delayed; nevertheless, they concentrate their analysis, precisely on this biophysical impact I have mentioned

In this context many doubts and controversies appear in the architect's work and his duty to the natural environment. At the same time, it is necessary to ask what ethical implications the architectural project has with man himself and the community of which he is part, and, ultimately, to whom architecture gives 
shelter. What exactly does sustainability mean in the architectural arena? What duties or obligations do the architect and his project have to the nature and culture of the place where the project is set? Is it because of the great deterioration of natural conditions as a whole that these issues should pre-determine the architectural object? Is it correct to speak of a sustainable architecture when biophysical and ecological aspects are first in line, over its social and cultural characteristics?

This gives way to an important paradox. Those who strongly support sustainable practices from the dominating biophysical standpoint criticize the cultural stances for being anthropocentric. These stances put human needs (intangible, spiritual, symbolic) above the natural laws that govern logically all ecosystems, of which man is one of many parts. However, the idea of considering nature before human needs is, in itself, much more anthropocentric than it seems at first sight, given that what is at stake is the survival of all natural ecosystems, including mankind. Even those apparently extreme stances - on one side the "naturalistic" point of view, and, on the other, the "scientific" posture, which both defend the radical conservation of nature- represent a materialistic approach. What happens to the human part, the part that distinguishes human nature, that gives meaning to life, that goes beyond our need for solely biological survival, and values nature for what it represents, creates, inspires or motivates. Is not this part of human "survival" also one of the basic needs that architecture has to satisfy?

Why should we conserve nature? Is it because, in doing so, we contaminate less and guarantee human survival, or is it simply because we find immense beauty, aesthetic delight, or profound peace in nature that is worth experiencing? Looked at in this way, the biophysical stance, a materialistic approach, seems much more anthropocentric in terms of searching for a concrete and tangible benefit for mankind. The cultural stances, on the other hand, might be more romantic and idealistic, but much more respectful of nature, in considering its existence in its own right.

The mentioning of all this leads us to question the specialization in architecture where a sort of environmental engineering is being applied. This specialization promotes the use, organization, management and reproduction of the natural environment in a more technical and efficient way. However, architecture that creates places for human dwelling that, as Le Corbusier believed, must provoke emotion and not just be functional, also relates man with nature in much more profound ways because of its beauty, its texture, its history, its meaning, its color, its smell - all of these possible thanks to man's ability of conscious perception.

What I am trying to emphasize is that sustainable architecture should depart from man, from his needs, his experience, his perception, memory, beliefs as an individual and as a society and, at the same time, from the knowledge and valuation of the ecosystems, the biophysical features of nature and landscapes that we use and, especially, from the relationship between them. This does not imply an anthropocentric vision. On the contrary it may be the way to achieve real possibilities for the conservation of nature through a more conscious and 
informed experience of its presence. I believe, as a hypothesis for the moment, that sustainability in its present terms will contribute to separate man and nature by dominating and exploiting nature in a more rational way. Even if we are able to reproduce all natural systems some day and are able to guarantee human survival, then nature will have ceased to exist and only man, that is artifice, will prevail.

\section{Towards a dialogical sustainability in architecture}

This essay focuses on the always polemic encounter between the built and natural environments, seeking to establish that architecture's role is to relate physically, but mainly in a cultural way, man and his natural settings. The idea is that man's intangible perception of and experience with nature, be it poetic, symbolic or abstract, are as important as preserving all its biophysical potential. So, if we consider that the main practices in sustainable architecture in recent years are dominated by ecological parameters as well as the technological paradigm, the central thesis that this investigation explores is that a dialogical design process relates natural conditions (physical and tangible) with human factors (subjective and intangible) on a mutual and equal basis by considering them as indispensable socio-cultural needs for a sustainable architecture in the present and in the future.

A dialogical vision of architecture, of sustainable development itself, takes a main role when proposing to transfer the Bajtinian concept of dialogue, understood as the most important way in which individuals of a specific society communicate with each other - that every individual expression is the result of an intense interaction and synthesis of various 'voices' from our past and present as a model to analyze architecture and to try to build a bridge between man and nature and, in this way, through the recognition and evaluation of the ethical, logical and aesthetic dimensions of an architectural whole, seek to understand its role as the dwelling space of man and to try, in Bajtin's words, 'to discover the interior unity of meaning' that sustains a building in a specific place and culture:

The dialogical analysis of architecture discovers it as a bridge between social sciences and physical sciences, or social history (history) and the history of earth (cosmology). This bridge cannot be insensible to human need and to human survival(...) it should include social needs for survival: peace, beauty, life, health etc. Physical dialogue is insufficient, we also need social dialogue [4].

How does architecture respond to this 'dialogical' world and not as a mere 'thing', to put it in Bajtinian terms? The main argument to defend this approach in architecture is to take the original dualistic start point between the natural and the artificial: real space, cosmic time get to "be" because there is, in the first place, a consciousness of its existence (subjective), and, after that, a communication of that existence (inter-subjective); simultaneously, there is a positioning of 'myself' in relation to 'us' and to an 'other' inside this objectified 
world. In this way, a represented world is added to the real world, and to cosmological time, a historical time appears. These are categories that define human culture, thanks to our double ability of consciousness and communication, of interpreting and dialoging, beginning an always unfinished chain of listening- understanding-responding process.

Using this conceptual framework, the main objective is to try to build into the dominant trend of environmental sustainability in architecture a dialogic approach. In this approach subjective perception and experience and the collective and inter-subjective valuation of nature as a physical and tangible existence as well as metaphysical and intangible presence are considered as indispensable parameters for sustainable design. Nature is still the main actor, architecture the means to speak with and about her, not only as something given of immutable laws, geological time or ecological processes, but also as a being in and of itself of changing values, as container of experience through collective memories, of creative inspiration, in other words, as a unity of materiality and meaning.

S. Kellert [5] establishes quite clearly that sustainable, green or, in general, ecological building processes "will not achieve its full promise and potential until it more positively motivates individuals, developers and planners by capturing in the built environment the widest range of physical, emotional, and intellectual values of nature".

This integral concept has also been proposed in similar terms by different authors, agreeing in the first place that architecture is a complex mix of aesthetic, ethical and logical factors. Thompson [6] proposes a system of ethical and aesthetical values for landscape architecture, and names them as a trilogy among the aesthetic, the social and ecology. With this in mind he establishes that there is univalent design (what we've called monological design as opposed to a dialogical one), those who work around one of the three components; bivalent, that includes two of the possible architectural dimensions; and, of course, trivalent design, that includes all three.

A closer idea to the concept of dialogue is explained by Benet et al. [7], establishing that there is no one style or kind of design that can be described as truly 'sustainable', nor is there a process or method that can guarantee an optimal design because architecture, being a cultural product, must be judged and assessed as an integral unity that has multiple objectives and origins. Trying to overcome these difficulties in this sustainable framework, they consider sustainable architecture as a responsive cohesion: an answer to different participants or stakeholders (user, nature, future generations, program etc.); cohesive because it includes, balances and orders in the architectural object all these answers. But one thing that they do believe is important is the order these dimensions should have, giving ecological processes first place, then the social. This, I believe, is contradictory to a responsive attitude, where the dialogue itself between stakeholders, participants or general conditions of place, is what establishes, in each specific situation, the best possible answer and order. They conclude the following idea: 
So after all there is nothing unique about how we should approach the making and identification of sustainable architecture; this is the way good design should be (...) it is [sustainability] a reconceptualization of architecture in response to a myriad of contemporary concerns about the effects of human activity [7].

Thwaites [8], on the other hand, uses the expressivist theory as a conceptual framework in order to evaluate the relationship between architecture and natural environment, not only as a physical product, but also as a way through which man expresses creative desires and aspirations. Again, we can see this fundamental idea of a human communication process: "In this context, design is a means of conceiving and communicating ideas: a dialogue rather than simply a method for solving specialized site-based problems, or specifically for prescribing style".

So, if these ideas, are apparently quite clear in accepting the multiple characteristic of all context with cultural and biophysical components, why speak of this urgent need to change towards a sustainable architecture?

Sustainable architecture should not tend, in my opinion, towards an environmental engineering or management methodology, what Thompson describes as univalent design (monoligic); instead it should defend and improve its integrative process, trivalent design, topogenetic dimensions, dialogical approach; in other words, it should be sustainable in relation to the individual who dwells, to society that produces, and to the natural setting that allocates architecture.

The main idea is not to describe how architecture is incorporated into nature, but rather how man relates to nature through his architecture.

Dialogic architecture recognizes the singularity of each project and of each built place, not as an experience or object isolated from history or social life, on the contrary, as dimensioned and materialization of aesthetic, scientific and political values of a same and specific social dialogue, and because of this universal and permanent [9].

We can understand, then, this "integral sustainability" as the satisfaction of bio-physical and socio-psychological human needs that allow the preservation, use and experience of nature through architecture, focused on improving man's quality of life without reducing future generations' possibilities to live with these same conditions and enjoy a rich, beautiful, creative, interesting, clean, healthy and balanced environment

In short, architecture, in order to be sustainable, that is, really sustainable and simply good, must satisfy simultaneously all architectural dimensions: logical (science, technical, functional) ethical (security, low impact, protection, good use) and aesthetic (beauty, meaning, emotion) dimensions.

\subsection{Dialogical assessment}

In the last few years sustainable architecture assessment systems have achieved great importance, not only aimed to measure the environmental impacts of the 
building, but also as tools that help establish strategies and make better decisions in the design process.

Nevertheless, it is very important to point out that most of these methods concentrate on the physical impacts on the natural environment. In a relatively recent investigation many of these assessment programs applied in the UK, USA, Norway, Sweden and France were reviewed, concluding as one of their main problems, the following:

However, none of the systems reviewed [BREAM, LEED, ESCALE, Ecoprofile, Ecoeffect] in this paper includes social and economic indicators of sustainability; all concentrate on physical and environmental aspects of sustainability [10].

Most of these tools are essentially quantitatively orientated, assigning grades or points, usually with a numerical scale, sometimes of appreciation (bad, regular, good, very good, excellent) to determine the building's environmental performance.

We are back to the main thesis I am trying to defend: sustainability is a way, a means to achieve a better life quality for society as a whole, not a goal in itself. Architecture must take into account its responsibility to the 'direct' users of the building, to those who live and use it, to those who perceive it as part of the city on a daily basis, in other words, as part of their daily environment. What kind of impact does the building have on the inhabitants? In which ways does architecture relate the users with the natural surroundings in tangible and intangible ways?

The difficulty is evident. There are no recipes or methodology that guarantees a predetermined result. Even if we could have a 'total' assessment system that takes into account all the variables, all items, it could become a way to guide, control and determine the results. Probably the best idea is to maintain diverse and different possibilities of evaluation and interpretation - some orientated to the tangible values, others aimed at explaining the meaning or the subjective perceptions of a place- in order to keep the many points of view that contribute to understanding our polycentric reality. Complementary assessment methods focused on the human dimension of sustainable architecture in order to understand and interpret intentions, values, experience, perceptions of nature through our built environment, seem necessary. Cole [11] points out this issue quite clearly: "Environmental assessment methods must accommodate both quantifiable performance criteria (such as annual energy use, water use, or greenhouse gas emissions) and more qualitative criteria such as the ecological significance of the site (...) the qualitative criteria can typically only practically be evaluated on a 'feature specific' basis...".

With this in mind, the proposal of this investigation is to outline a dialogical assessment method for sustainable architecture. This method can be a tool to help in the understanding of place by interpreting the communicative process that architecture, as material space, and people, through social use of architecture, establish with the natural environment. The idea is that a dialogical architecture must engage in this communicative process, and RESPOND to the "voices" of the natural and cultural context, demonstrating a listening- 
understanding-answering process that adds a new portion to the dialogue, always unfinished, that human development implies.

In first place, dialogue with the natural settings can be registered through the interpretation and valuation of the experience and perception that the inhabitants have through the use of an architectural space. It is in the dialogue between object and subject, thanks to the dialogical significance that society imbues to nature and architecture, that we value, understand, use or visualize them.

On a second level, a dialogical architecture can be defined by relating and comparing the initial intentions that the architect incorporates into the project (by listening-understanding-responding to the 'voices of the natural and cultural context') with the experience of the users of the real place. The main objective is to detect the inter-subjective dialogue (architect and user) that architecture makes possible, focusing on the natural settings of the environment.

With these parameters, a good architecture, an integral sustainable architecture, allows an intense, interesting and satisfactory experience of the natural factors of the place, an intentional situation that is anticipated by the project, not as imposition, but rather as possibility.

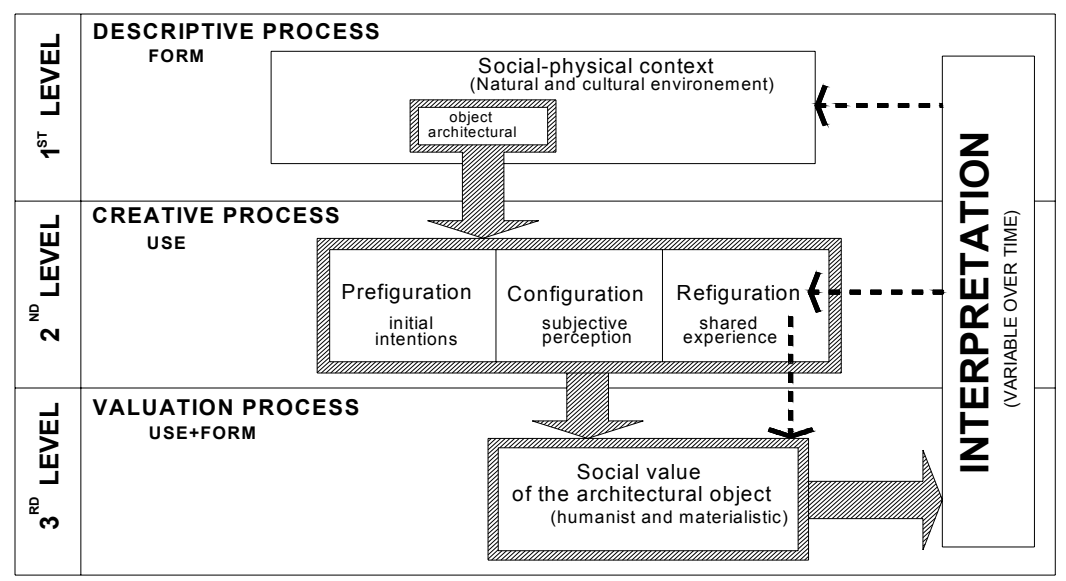

Figure 1: Dialogical assessment model for sustainable architecture.

Figure 1 explains the interpretative process that is proposed: a first level that has to do with the description of the place, the architecture, the settings -basically the form and material characteristics; in second place, the evaluation of the whole creative process, that is, the architectural project that contains the initial intentions of the designing team and or participants (prefiguration of place), the experience of the built place on a subjective, that is, individual scale (configured place), and finally, the inter-subjective experience of the place verified by social use and communication (refiguration of place); in third place, the valuation of the former two experiences that conclude in a general interpretation of the human dimensions of architecture, an interpretation that is constantly changing over time. 


\subsection{Dialogical architecture}

In modern architectural practice there are many examples of this capability of reading, listening and responding in an integral manner, based on an architectural tradition that knows how to listen, understand, interpret and, of course, answer the best way possible in that specific moment. Just by naming Gaudí, Aalto, Wright or Barragan we can exemplify this practice. But even today, we may see extraordinary examples in this sense. Analyzed with this dialogical approach, environmentally responsible architecture designed by architects Zumthor, Miralles and Pinòs, Schjetnan and Latz, are understood and enjoyed in all their architectural quality. Far from finding how they are similar in their relation to the place, the immense and rich differences that characterize each one emerge as possibilities of experience, never as predetermined experiences between man and nature.

With this dialogical approach it is possible to sense how Zumthor's thermal baths in Vals is more aesthetically strong, where nature is experienced in a kind of phenomenological poetry, taking direct advantage of the extraordinary features of the natural landscape.

Miralles and Pinos Igualada Cemetery recreates nature through an architecture that delivers a more metaphysical and introspective perception, firmly anchored on archaic beliefs of life and death.

In Duisburg, the factory's structure of an old industrial ensemble, clearly identified as the destroyer of the environment, proposes new ways for the machine and nature to relate, without destroying one another, a sort of ethical compromise that $\mathrm{P}$. Latz and his design team clearly assume.

In Xochimilco ecological park, on the other hand, the structure is the underlying nostalgic replenishment (nostalgic in the Barragan's sense, that is, the consciousness of the past, but elevated to the power of poetics) restoring an ancient interaction between society and natural settings, deeply rooted in collective memory.

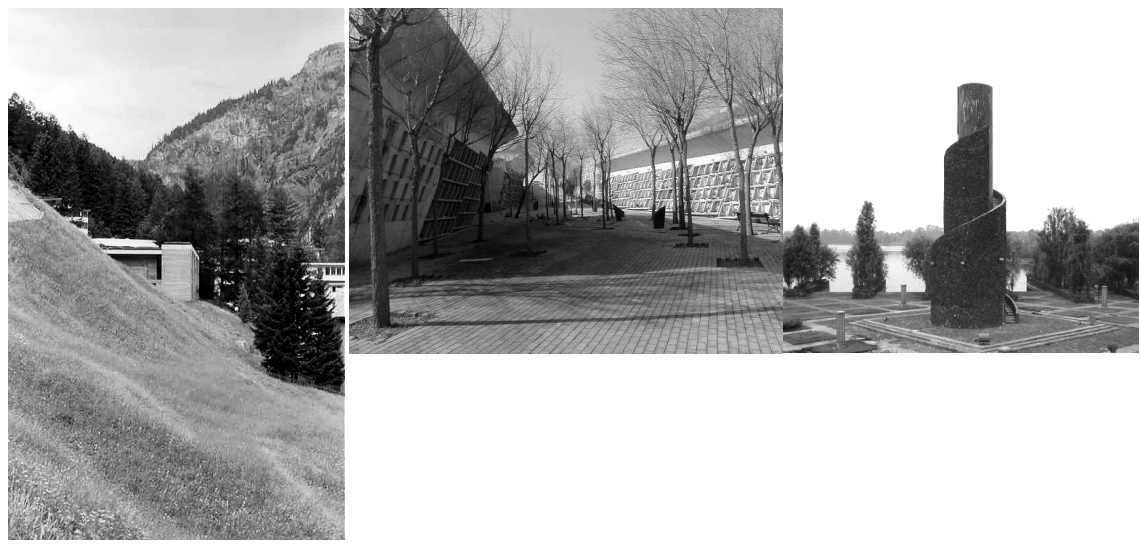

Figure 2: From left to right: Vals Termal Baths, Igualada Cemetery and Xochimilco Ecological Park. 
Each one is specific, all contribute to conserve the physical environment (the materialistic evaluation was quite constant in all four projects), there is richness in that there was concentration on the the less tangible relations that these architectures provoke between man and nature. It is this dialogical approach the means that help interpret and value the physical and intangible relationships with nature of a specific site.

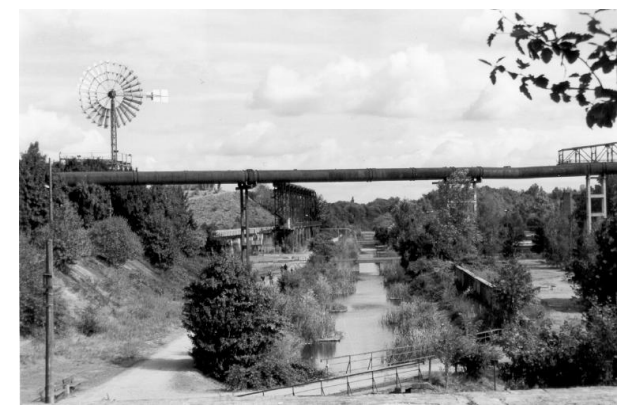

Figure 3: Duisburg Landscape Park.

In this perspective, the responsibility of the architect should be, in any case, inclusive, open to dialogue, open to as many possibilities, including, of course, the environmental degradation that worries modern society so much. In short, architects should incorporate the natural in a fundamental manner into their project in order to affect mind and body as a way to improve and intensify our relationship with nature, through architecture - an experience that might be an important way to increase society's awareness of the urgent need to preserve and respect nature.

\section{References}

[1] Bajtin, M.M.; The Dialogic Imagination; University of Texas Press; Austin, 1998

[2] Ricoer, Paul; Arquitectura y Narratividad; In Arquitectonics. Mind Land and Society. No. 4 Arquitectura y Hermenéutica; Edicions UPC, Barcelona, 2003

[3] Luxán García de Diego, Margarita; Arquitectura de vanguardia y ecología ; In: Ciudades para un futuro más sostenible Boletín CF+S. Número 5. Abril 1998.Madrid. http://habitat.aq.upm.es/boletin/n5/amlux.html

[4] Muntañola, Josep; Arquitectura, modernidad y conocimiento; Arquitectonics; Edicions UPC; Barcelona; pp.143, 2002.

[5] Kellert, Stephen R. Ecological challenge, human values of nature, and sustainability in the built environment; In: Kibert, Charles; Reshaping the built environment. Ecology, ethics and economics.; Island Press; Washington D.C.; pp. 40, 1999 
[6] Thompson, Ian; Ecology, community and delight. Sources of values in landscape architecture. E \& FN SPON; London. pp 178-179, 2000.

[7] Benet, Helen; Radford, Antony and Williamson, Terry; Understanding sustainable architecture; SPON Press; London; pp.126, 2003.

[8] Thwaites, Kevin; Expressivist Landscape architecture: The development of a new conceptual framework for landscape architecture; En revista Landscape Journal; Vol. 19, No. 1-2 2000, University of Wisconsin Press, Madison; pp. 207, 2000.

[9] Pol, Enric et. al.; La evaluación post-ocupacional (POE) de edificios, una reflexión crítica de su uso: nuevos criterios de sostenibilidad; En Ciudad y Medio ambiente desde la experiencia humana.V Congreso de Psicología Ambiental; Universitat de Barcelona; Barcelona, pp. 240,1996

[10] Crawley, Drury et. al.; Comparative assessment of environmental performance tools and the role of the Green Building Challenge; Building Research \& Information; Special Edition, Vol. 29, No. 5; pp 340, Sept-Oct 2001;

[11] Cole, Raymond; Environmental Performance of buildings: setting goals, offering guidance and assessing progress; In Reshaping the built environment. Ecology, ethics and economics. Island Press; Washington D.C.; pp. 286, 1999. 